Sains Malaysiana 49(5)(2020): 1201-1208

http://dx.doi.org/10.17576/jsm-2020-4905-25

\title{
G-Jitter Fully Developed Heat and Mass Transfer by Mixed Convection Flow between Two Parallel Plates with Constant Heat Flux
}

(Ketar-G Pemindahan Haba Terbentuk Penuh oleh Aliran Olakan Campuran antara Dua Plat Selari dengan Fluks Haba Tetap)

\author{
Wan Nor Zaleha Amin, Ahmad Qushairi Mohammad, Sharidan ShafiE* \& Muhammad Qasim
}

\section{ABSTRACT}

In this research, the problem of heat and mass transfer in mixed convection flow induced by g-jitter is studied analytically. The flow passes through an infinite length of vertical parallel plates. The left wall of the plate is prescribed with constant heat flux while the right wall is maintained at a constant temperature. The governing boundary layer equations are transformed into dimensionless equations by using the appropriate dimensionless variables. The behaviors of the velocity, temperature, and concentration profiles of the fluid are analyzed by Fourier method and illustrated graphically as well. Results show that due to an increase in value of wall temperature, the fluid temperature increases. It is found that the controlling parameters strongly affect the heat and mass transfer characteristics in g-jitter fluid flow.

Keywords: Constant heat flux; g-jitter; mixed convection; two vertical plates

ABSTRAK

Dalam kajian ini, masalah bagi aliran pemindahan haba dan jisim di dalam aliran olakan campuran yang disebabkan oleh ketar-g dikaji secara analitik. Aliran ini melepasi satu plat selari menegak yang panjangnya tidak terhingga. Dinding sebelah kiri plat ditetapkan dengan fluks haba tetap manakala dinding sebelah kanan pula dikekalkan pada suhu tetap. Persamaan menakluk bagi lapisan sempadan diubah ke dalam persamaan tak bermatra dengan menggunakan pemboleh ubah tak bermatra yang bersesuaian. Telatah bagi profil halaju, suhu dan kepekatan bendalir dianalisis dengan kaedah Fourier dan juga diilustrasi secara bergraf. Keputusan menunjukkan bahawa dengan peningkatan nilai suhu dinding, suhu cecair juga meningkat. Didapati bahawa parameter pengawal sangat mempengaruhi ciri pemindahan haba dan jisim dalam aliran bendalir ketar-g.

Kata kunci: Dua plat menegak; fluks haba tetap; ketar-g; olakan campuran

\section{INTRODUCTION}

The mechanisms of convection include free, forced, and mixed. Among these three types, mixed convection is the most highlighted topic and is considered here. Scientists are still interested to disclose the characteristics of mixed convective fluid behavior due to its promising significance in various engineering and industrial procedures. Mixed convection concepts are useful in designing the cooling system with liquid metals, accelerators, nuclear reactor, pumps, and blood flow. These motivated numerous researchers such as Bakar et al. (2019), Chen (2004), Hammou et al. (2004), Kumari and Nath (2004), Kumar et al. (2009), and Sajid et al. (2010) explored the behavior of mixed convection flow in vertical plates through different methods to increase the concentration and temperature transfer performance of fluids.

Furthermore, space experiments have showed the unknown or nonexistent effect of g-jitter or residual acceleration associated with the microgravity environment. g-jitter is defined as the inertia effects due to quasi-steady, oscillatory or transient accelerations arising from crew motions and machinery vibrations in parabolic aircraft, space shuttles or other microgravity environments. It is important to understand the effects of g-jitter in design and maintaining the cooling board of a system to prevent such overheating cause problem like explosion in practical application. Recently, numerous attempt by Rawi et al. (2018, 2017a, 2017b) was conducted with the numerical research for the effect of g-jitter upon the mixed convection flow to overcome this situation.

Despite that, constant heat flux in an isothermal state is also desirable in many applications especially for an electric component in the circuit board. Therefore, a numerical study by Chen et al. (2000) of the fully developed mixed convection in a heated vertical channel filled with a porous medium with imposed uniform heat 
flux at the plates was performed using the Brinkman Forchheimer extended Darcy model. It is then being solved using the Galerkin method. Next, Lee et al. (2004) presented a research on a large eddy simulation of heated vertical annular pipe flow in fully developed turbulent mixed convection with heat flux. Navier Stokes equations are solved using a second order of finite volume method. The results showed that the strong heating and buoyant force affect the flow structure by reducing the turbulent intensities, shear stress, and turbulent heat flux, particularly near the wall. The strong heating near the inner wall causes an increased viscosity and the consequential enhancement in the damping of turbulence.

Also, Sivasamy et al. (2010) conducted a research of jet impingement cooling of constant heat flux on the mixed convection flow of a porous channel numerically using Darcy model and found that the increasing values of Grashof and Reynolds numbers will increase the Nusselt number. Later, Roşca and Pop (2013) studied numerically the mixed stagnation point past vertical plate with second-order slip using bvp4c from Matlab with constant heat flux. The paper performed a stability analysis to verify the stability of the results and found out that the second order slip considerably affect the heat and flow characteristics.

Moreover, Altunkaya et al. (2017) conducted a research to investigate analytically the open-ended vertical microchannel using a perturbation technique with constant heat flux. The author considered the analysis for Nusselt number against the mixed convection parameter, rarefaction, and viscous dissipation. The results showed that as the mixed convection and rarefaction increases, Nusselt number is decreasing.

Recently, Rosas et al. (2017) conducted an experimental study of mixed convection heat transfer which is carried out in a vertical channel with onesided semi-cylindrical constriction with prescribed heat flux while the other bounding wall is insulated and adiabatic. The results showed that variation of the local temperature distributions with angular position and spanwise location become evident and their relation to the presence of a complex $3 \mathrm{D}$ vortex structure that develops close to the semi-cylindrical constriction. Moreover, empirical correlations for the overall Nusselt number are obtained using both Reynolds and Grashof numbers as controlling parameters.

These review of literature suggests that little attention has been paid to evaluate the mixed convection in discretely heated surfaces. Clearly, from the foregoing discussion, there are no prior results available for mixed convection heat and mass transfer between two vertical plates with the effect of g-jitter by a prescribed heat flux boundary condition. Heat flux is relevant to influence heat and mass transfer rates. In particular, this research aims to employ Fourier method and also to expand the following works by Sharidan et al. (2005) which investigate analytically the effect of g-jitter on mixed convection flow in two vertical parallel plates with constant wall temperature boundary condition. Moreover, this study is very crucial to explore the effect of g-jitter and heat flux for understanding the fluid flow behavior in microgravity environment.

\section{FORMULATION AND METHODS}

Consider an incompressible fluid which unsteadily flows between two vertical parallel plates of width $h$, uniform temperature at the right wall and heat flux at the left wall. A stationary Cartesian coordinate is chosen such that the $x$-coordinate extend along the surface and $y$-coordinate is normal to it. Pressure gradient of oscillatory type is applied in the flow direction. The presence of $\mathrm{g}$-jitter fully developed effect is also considered. Assuming time $t=0$, the flow is at constant temperature $T_{0}$, concentration $C_{0}$ with the mean velocity $u_{0}$ and pressure $p_{0}$. The assumption of fully developed flow means that the axial ( $x$-direction) velocity depends only on the transverse coordinate $y$. Then, from the continuity equation, the transverse velocity $v$, must be zero. The axial velocity $u$, and the fluid temperature $T$, and concentration $C$, are assumed to be functions of $y$ plus function of time $t$. The pressure variation is found to be a linear function of $x$ and $t$, and it is assumed that the gravity acceleration is given by $g^{*}(t)=g_{0} \sin (\omega t)$ where $g_{0}$ is the magnitude and $\omega$ is the frequency of the g-jitter field.

In the view of these assumptions, the initial and boundary layer conditions governing the mixed convection flow of the fluid past a vertical parallel plate containing continuity (Kamal et al. 2019), momentum, energy, and mass equations (Naser et al. 2013; Rajvanshi \& Saini 2010) can be cast into the following forms:

$$
\nabla \cdot \boldsymbol{u}=\frac{\partial u}{\partial x}+\frac{\partial v}{\partial y}=0
$$

$$
\begin{gathered}
\rho \frac{\partial u}{\partial t}=-\frac{\partial p}{\partial x}+\mu \frac{\partial^{2} u}{\partial y^{2}}+g^{*}(t) \rho\left[\beta_{T}\left(T-T_{0}\right)+\beta_{C}\left(C-C_{0}\right)\right], \\
\frac{\partial T}{\partial t}=\frac{k}{\left(\rho c_{p}\right)} \frac{\partial^{2} T}{\partial y^{2}} \\
\frac{\partial C}{\partial t}=D \frac{\partial^{2} C}{\partial y^{2}} .
\end{gathered}
$$

The appropriate initial and boundary conditions are given by

$$
\begin{array}{lcccc}
t \leq 0: & u=u_{0}, T=T_{0}, & C=C_{0} & \text { for } & 0<y<h \\
t>0: & u=0, \frac{\partial T}{\partial y}=-\frac{q}{k}, & C=C_{1} & \text { at } & y=0 \\
& u=0, T=T_{2}, & C=C_{2} & \text { at } & y=h
\end{array}
$$


where $D$ is the mass diffusivity, $\mu$ is the dynamic viscosity of the fluid, $\rho$ is the fluid density, $\beta_{T}$ and $\beta_{C}$ are the volumetric coefficient of thermal expansion and concentration of the fluid respectively, $v$ is the kinematic viscosity, $p$ is the fluid pressure, $k$ is the thermal conductivity of the fluid, $c_{p}$ is the specific heat of the fluid of the constant pressure, $q$ is the heat flux, $h$ is the width between two plates, $C_{1}$ is the concentration of the left wall and $T_{2}$ and $C_{2}$ is the temperature and concentration of the right wall respectively. The flow configurations and coordinate system are shown in Figure 1.

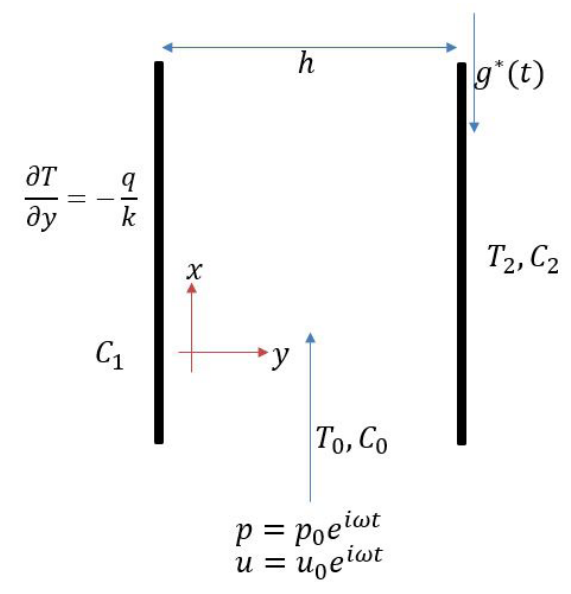

FIGURE 1. Flow configuration of heat and mass transfer and coordinate system between two vertical plates

Then, Equations (2), (3) and (4) are transformed into the following dimensionless equations (Sharidan et al. 2005)

$$
\begin{gathered}
\frac{\partial U}{\partial \tau}=-\frac{\partial P}{\partial X}+\frac{\partial^{2} U}{\partial Y^{2}}+\frac{G r}{R e} \cdot g(\tau) \cdot[\theta+N \varphi], \\
\frac{\partial \theta}{\partial \tau}=\frac{1}{P r} \frac{\partial^{2} \theta}{\partial Y^{2}} \\
\frac{\partial \varphi}{\partial \tau}=\frac{1}{S c} \frac{\partial^{2} \varphi}{\partial Y^{2}}
\end{gathered}
$$

where the dimensionless variables are defined as

$$
\begin{gathered}
U=\frac{u}{u_{0}}, \tau=\frac{v t}{h^{2}}, P=\frac{h p}{\rho v u_{0}}, X=\frac{x}{h}, Y=\frac{y}{h}, \theta=\frac{T-T_{0}}{h q / k}, \varphi=\frac{C-C_{0}}{C_{2}-C_{0}}, g(\tau)=\frac{g^{*}}{g_{0}}, \\
N=\frac{\beta_{T}\left(C_{2}-C_{0}\right)}{\beta_{C}\left(\frac{h q}{k}\right)}
\end{gathered}
$$

with Grashof number $G r$, Reynolds number Re, Prandtl number $\mathrm{Pr}$ and $\mathrm{Schmidt}$ number $\mathrm{Sc}$ are given by

$$
G r=\frac{g_{0} \beta_{T} q h^{4}}{k v^{2}}, R e=\frac{u_{0} h}{v}, \operatorname{Pr}=\frac{v \rho c_{p}}{k}, S c=\frac{v}{D} .
$$

Dimensionless boundary conditions are:

$$
\begin{array}{llllc}
\tau \leq 0: & U=1, \theta=0, & \varphi=\varphi_{0} & \text { for } & 0<Y<1 \\
\tau>0: & U=0, \frac{\partial \theta}{\partial y}=-1, & \varphi=r_{C} & \text { at } & Y=0 \\
& U=0, \theta=r_{T}, & \varphi=1 & \text { at } & Y=1
\end{array}
$$

Parameter of dimensionless wall temperature and concentration $r_{T}$ and $r_{C}$ are defined as

$$
r_{T}=\frac{T_{2}-T_{0}}{h q / k}, r_{C}=\frac{C_{1}-C_{0}}{C_{2}-C_{0}}
$$

Using Fourier method, (7) and (8) have the solution of form

$$
\begin{gathered}
\theta(Y, \tau)=1+r_{T}-Y, \\
\varphi(Y, \tau)=r_{C}+\left(1-r_{C}\right) Y .
\end{gathered}
$$

Assuming $U=e^{i \Omega \tau} \Phi(Y), P=e^{i \Omega \tau} F(X)$ and $g(\tau)=$ $e^{i \Omega \tau}$ (Sharidan et al. 2005) along with overall mass conservation equation $\int_{0}^{1} \Phi(Y) d Y=1$, then the solution of $\Phi(Y)$ is given by

$$
\begin{gathered}
\Phi(Y)=\frac{1}{\beta^{2}}\left\{\left(\frac{\partial F}{\partial X}-\frac{G r}{R e}\left[1+r_{T}+N \cdot r_{C}\right]\right) \frac{\sinh (\beta(1-Y))}{\sinh \beta}+\left(\frac{\sinh \beta Y}{\sinh \beta}\left\{\frac{\partial F}{\partial X}-\frac{G r}{R e}\left(r_{T}+N\right)\right\}\right)\right. \\
\left.+\frac{G r}{R e}\left[1+r_{T}-Y+N\left(r_{C}+Y-r_{C} \cdot Y\right)\right]-\frac{\partial F}{\partial X}\right\}
\end{gathered}
$$

where $\beta^{2}=\mathrm{i} \Omega$ with $\partial F / \partial X$ is given by

$$
\frac{\partial F}{\partial X}=\frac{\beta^{3} \sinh \beta}{2 \cosh \beta-\beta \sinh \beta-2}+\frac{G r}{R e}\left[\frac{1+2 \cdot r_{T}+N\left(r_{C}+1\right)}{2}\right] .
$$




\section{VALIDATION}

For validation purposes, the solutions of (13), (14) and (15) are then being substitute back to (6), (7), and (8) and found that the left-hand side, LHS of (6), (7) and (8) are equal to right-hand side, RHS, respectively. Solutions
(13), (14) and (15) are also observed fully satisfied the boundary conditions (11). Therefore, it is verified that the solutions of concentration (14), temperature (13) and velocity profiles (15) are corrects.

\begin{tabular}{clcc}
\hline Eqn. & \multicolumn{1}{c}{ Variables } & LHS & RHS \\
\hline$(8)$ & $S_{C}=0.3$ & 0 & 0 \\
$(7)$ & 0 & 0 \\
$(6)$ & $N=1, G r / R e=0$ & 0 & 0 \\
\hline
\end{tabular}

\section{RESULTS AND DISCUSSION}

The results are then computed into mathematical software named Matlab and the various values of the desired parameters are then generated and presented graphically. The quantities plotted along the vertical axis are temperature, concentration and velocity profiles which the equations of solutions are

$$
\begin{aligned}
& \theta(Y, \tau)=1+r_{T}-Y, \\
& \varphi(Y, \tau)=r_{C}+\left(1-r_{C}\right) Y,
\end{aligned}
$$

$\operatorname{Imag}\left(U=\Phi e^{i \Omega \tau}\right)=\operatorname{Real}(\Phi) \sin (\Omega \tau)+\operatorname{Imag}(\Phi) \cos (\Omega \tau)$

and it represents the value of driving force

$$
g^{*}(t)=\operatorname{Imag}\left(g_{0} \mathrm{e}^{i \omega t}\right) \text { and } u_{0}(t)=u_{0} \sin (\omega t)
$$

Figure 2 shows the effect of dimensionless concentration $r_{C}$ for the concentration profile. Values of ratio for $r_{T}$ and $r_{C}$ are taken in the range of 0 to 1 . It is shown that as $r_{C}$ increased, the concentration also increased. Meanwhile, Figure 3 demonstrates the effect of dimensionless wall temperature $r_{T}$ on temperature distribution. From the graph, as $r_{T}$ increases, $\theta$ also increases. This situation is attributable as $r_{T}$ and $r_{C}$ increases, more hot and less concentrated fluid are carried through the vertical plates faster due to the increasing fluid temperature which consequently results in higher wall temperature gradient. These imply that concentration and temperature ratio is directly proportional to the concentration and temperature distribution, respectively.
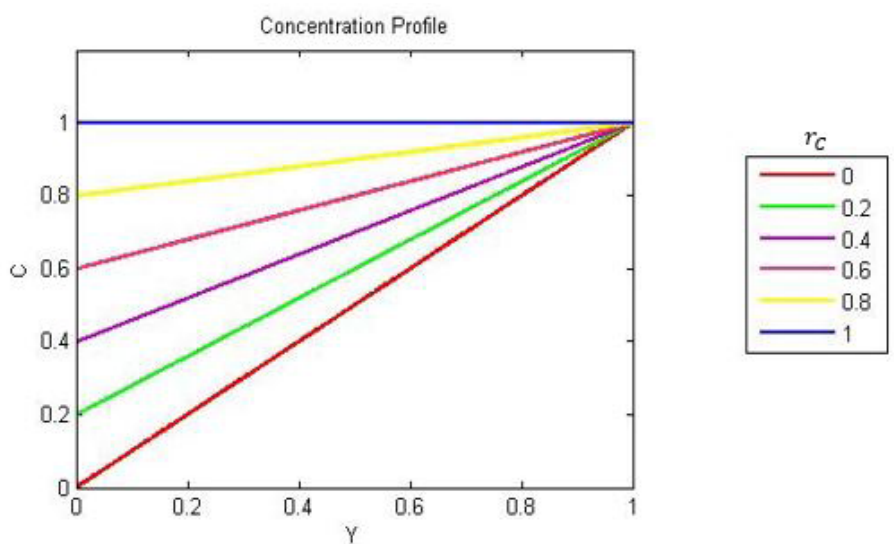

FIGURE 2. Concentration profiles for different values of $r_{C}$ 


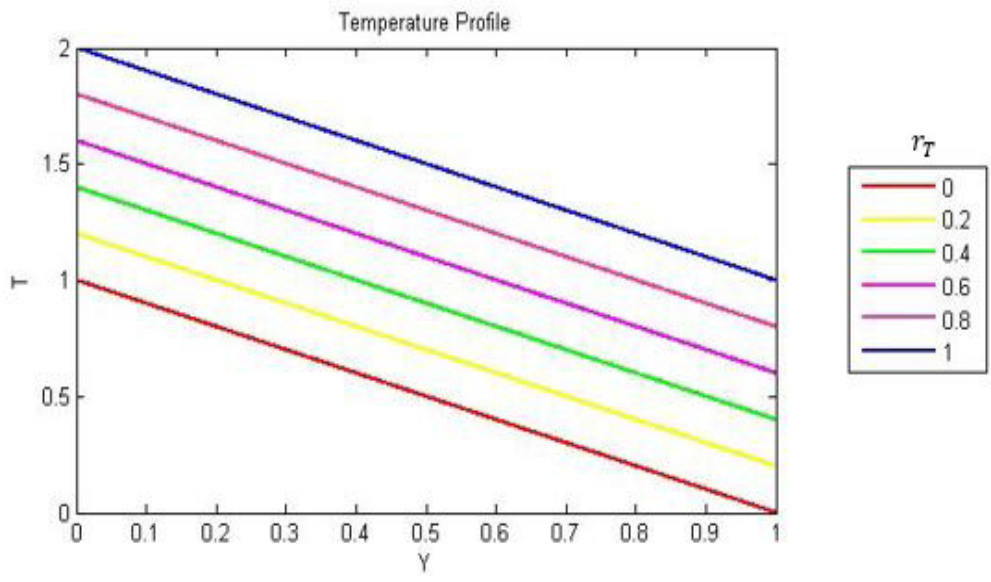

FIGURE 3. Temperature profiles for different values of $r_{T}$

From Figures 4 to 7 , graphical results for the velocity profiles are shown. The parameters incorporated in the problem are mixed convection $\mathrm{Gr} / \mathrm{Re}$, buoyancy ratio $N$, oscillating $\Omega \tau$, temperature and concentration ratio parameter $r_{T}$ and $r_{C}$.

The analysis on the effect of mixed convection parameter $\mathrm{Gr} / \mathrm{Re}$ on the fluid flow is shown in Figure 4. It is found that the velocity of the fluid increases when $\mathrm{Gr} / \mathrm{Re}$ increases. The velocity profile is always symmetric about the centerline of the channel at $Y=0.5$.
The presence of mixed convection enables us to seek the consequence of the relaxation time on the fluid velocity. This is because the mixed convection raised the wall temperature which drives the fluid to become further from the surface resulting the high speed of flow. It enhances the heat transfer when they assist the forced flow. This results indicates a good agreement with the past scheme (Mahat et al. 2017).

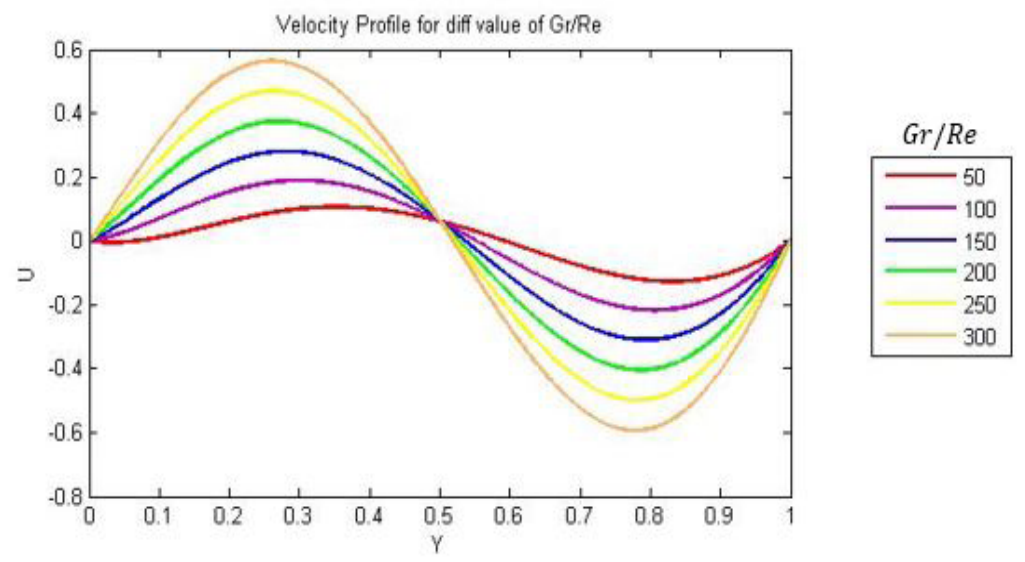

FIGURE 4. Velocity profiles for different values of when $\mathrm{Gr} / \operatorname{Re} N=0, r_{T}=0.5, r_{C}=0.5$,

$$
\Omega \tau=\pi / 4
$$

Furthermore, Figure 5 illustrates the velocity profile for different values of buoyancy ratio $N$. It can be seen that the fluid flow accelerated to the right wall as $N$ increases. This imply that the buoyancy aiding the fluid to move faster to upwards direction. 


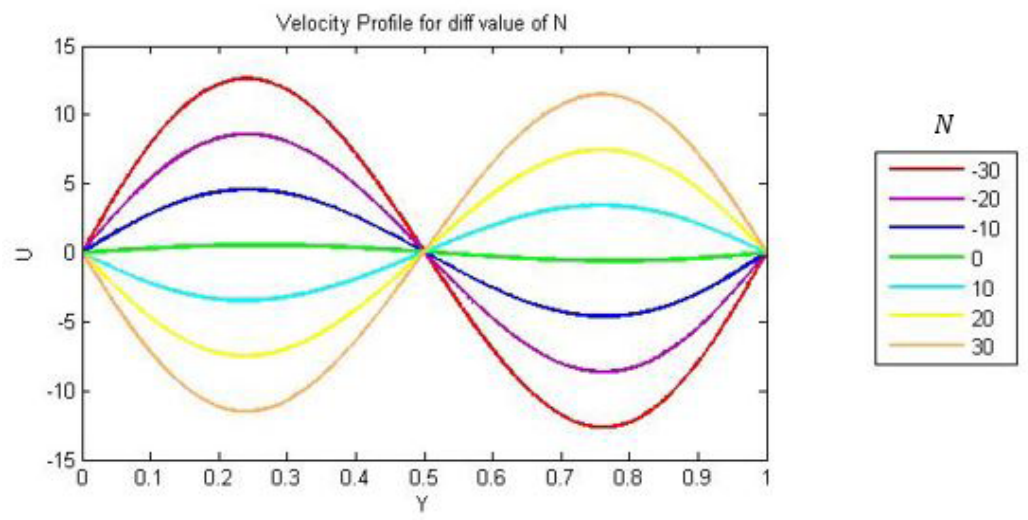

FIGURE 5. Velocity profiles for different values of when $\mathrm{Gr} / \mathrm{Re}=300, r_{T}=0.5, r_{C}=0.5$, $\Omega \tau=\pi / 4$

Figure 6 analyzes the effect of oscillating parameter $\Omega \tau$ towards the behaviour of the fluid velocity $U$. Values of $\Omega \tau$ is taken between 0 and $2 \pi$ because the same behaviors are shown for the increasing values of $2 \pi$. It is observed that there is an increasing reversed flow close to the left wall and only a small reversed flow closed to the right wall, respectively. This is due to the prescribed heat flux at the left wall where the fluid flow rises as the temperature increased. Moreover, the fluid velocity fluctuated as increases. It has a good correlation with the past results (Rawi et al. 2017c). The oscillating velocity has passed a quasi-steady state in a specific time about $2 \pi$ and subsequently it fluctuates with fundamentally the same frequency of the g-jitter. This is due to the velocity become nonlinear, following around the identical scheme as g-jitter modulation.

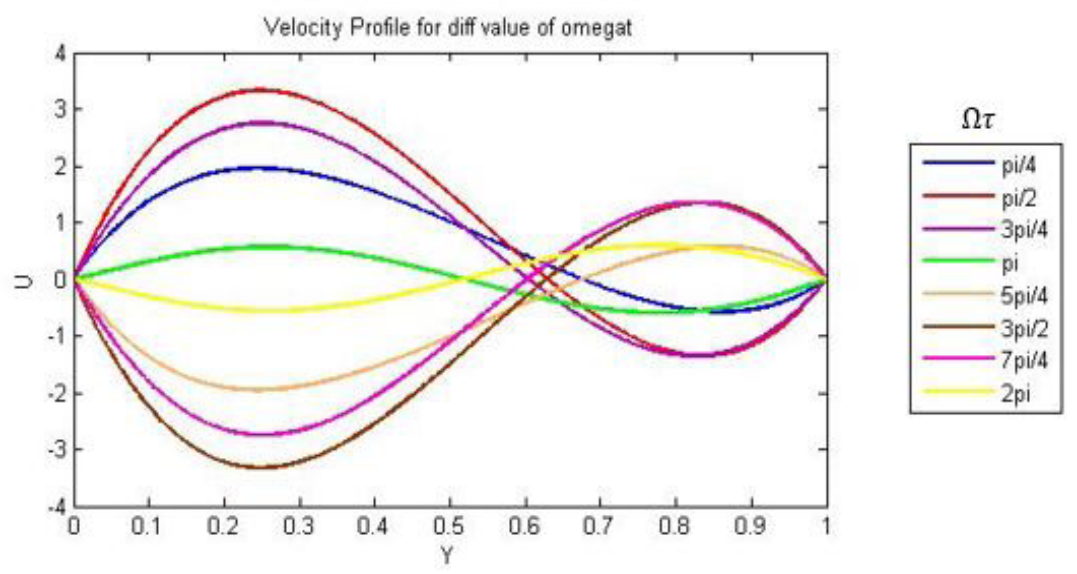

FIGURE 6. Velocity profiles for different values of $\Omega \tau$ when $\mathrm{Gr} / \mathrm{Re}=300, r_{T}=0.5, r_{C}=0.5$, $N=0$

Additionally, very interesting situations can be seen in Figure 7(a), where when $r_{T}>r_{C}$, the velocity profile showed a full reversed flow when the oscillating parameter $\Omega \tau$ is increased while in Figure $7(\mathrm{~b})$ it is partial reversed flow when $\Omega \tau$ increased as $r_{T}>r_{C}$. These flow behaviour are the same from those case where the constant wall temperature is implied by Sharidan et al. (2005). Physically, the oscillating parameter will affect the velocity profiles. 


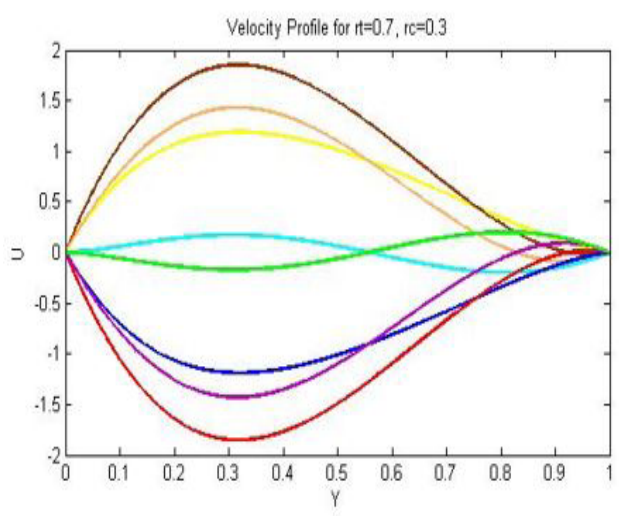

(a)

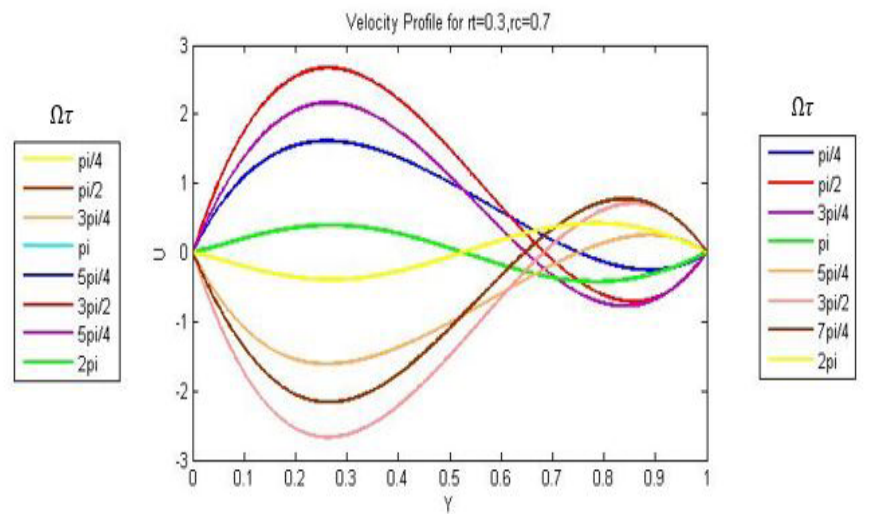

(b)

FIGURE 7. Velocity profiles for different values of $\Omega \tau$ when $\mathrm{Gr} / \mathrm{Re}=300, N=0$ with

$$
\text { a) } r_{T}=0.7, r_{C}=0.3 \text {; b) } r_{T}=0.3, r_{C}=0.7 \text {. }
$$

\section{CONCLUSION}

This paper focused on heat and mass transfer by mixed convection flow between two parallel plates with constant heat flux, in the existence of g-jitter effect. Therefore, the following conclusions are made based on present research. Due to the increasing value of the wall temperature $r_{T}$ and concentration ratio $r_{C}$, the temperature $\theta$ and concentration of the fluid increased. These two parameters attributed to improvement of heat transfer efficiency. It enhanced the fluid to flow faster as it is increases. For velocity distribution, the velocity $U$ of the fluid increased as mixed convection parameter $\mathrm{Gr} /$ Re and buoyancy ratio $N$ rised. Meanwhile, the velocity fluctuated with an increase in oscillating parameter $\Omega \tau$.

\section{ACKNOWLEDGEMENTS}

The authors would like to acknowledge the Ministry of Education (MOE) and Research Management CentreUTM, Universiti Teknologi Malaysia (UTM) for the financial support through vote numbers 5F004, 5F116, 07G70, 07G72, 07G76, 07G77, and $17 \mathrm{~J} 98$ for this research.

\section{REFERENCES}

Altunkaya, A.N., Avci, M. \& Aydin, O. 2017. Effects of viscous dissipation on mixed convection in a vertical parallel-plate microchannel with asymmetric uniform wall heat fluxes: The slip regime. International Journal of Heat and Mass Transfer 111: 495-499.

Bakar, N.A., Roslan, R., Karimipour, A. \& Hashim, I. 2019. Mixed convection in lid-driven cavity with inclined magnetic field. Sains Malaysiana 48(2): 451-471.

Chen, Y.C. 2004. Non-Darcy flow stability of mixed convection in a vertical channel filled with a porous medium. International Journal of Heat and Mass Transfer 47(6-7): 1257-1266.

Chen, Y.C., Chung, J.N., Wu, C.S. \& Lue, Y.F. 2000. Non-Darcy mixed convection in a vertical channel filled with a porous medium. International Journal of Heat and Mass Transfer 43(13): 2421-2429.

Hammou, Z.A., Benhamou, B., Galanis, N. \& Orfi, J. 2004 Laminar mixed convection of humid air in a vertical channel with evaporation or condensation at the wall International Journal of Thermal Sciences 43(6): 531-539.

Kamal, F., Zaimi, K., Ishak, A. \& Pop, I. 2019. Stability analysis of MHD stagnation-point flow towards a permeable stretching/shrinking sheet in a nanofluid with chemical reactions effect. Sains Malaysiana 48(1): 243-250.

Kumar, J.P., Umavathi, J.C., Pop, I. \& Biradar, B.M. 2009. Fully developed mixed convection flow in a vertical channel containing porous and fluid layer with isothermal or isoflux boundaries. Transport in Porous Media 80(1): 117-135.

Kumari, M. \& Nath, G. 2004. Mixed convection boundary layer flow over a thin vertical cylinder with localized injection/ suction and cooling/heating. International Journal of Heat and Mass Transfer 47(5): 969-976.

Lee, J.S., Xu, X. \& Pletcher, R.H. 2004. Large eddy simulation of heated vertical annular pipe flow in fully developed turbulent mixed convection. International Journal of Heat and Mass Transfer 47(3): 437-446.

Mahat, R., Rawi, N.A., Kasim, A.R.M. \& Shafie, S. 2017. Mixed convection boundary layer flow of viscoelastic nanofluid past a horizontal circular cylinder: Case of constant heat flux. Paper presented at the Journal of Physics: Conference Series.

Naser, N., Kasim, A.R.M. \& Aurangzaib, S.S. 2013. G-Jitter mixed convection on double diffusion adjacent to a vertical stretching sheet. Recent Advances in Mathematics 7: 174-181.

Rajvanshi, S.C. \& Saini, B.S. 2010. Free convection MHD flow past a moving vertical porous surface with gravity modulation at constant heat flux. International Journal of Theoretical and Applied Sciences 2(1): 29-33.

Rawi, N.A., Ilias, M.R., Jiann, L.Y., Isa, Z.M. \& Shafie, S. 2018. The effect of copper nanoparticles on mixed convection flow of jeffrey fluid induced by g-jitter. Journal of Nanofluids 7(1): 156-162. 
Rawi, N.A., Ilias, M.R., Isa, Z.M. \& Shafie, S. 2017a. Effect of gravity modulation on mixed convection flow of second grade fluid with different shapes of nanoparticles. Malaysian Journal of Fundamental and Applied Sciences 13(2): 132-136.

Rawi, N.A., Kasim, A.R.M., Isa, Z.M., Mangi, A. \& Shafie, S. 2017b. G-jitter effects on the mixed convection flow of nanofluid past an inclined stretching sheet. Frontiers in Heat and Mass Transfer 8: e99384.

Rawi, N.A., Amin, W.N.Z., Admon, M.A. \& Shafie, S. 2017c. G-jitter fully developed heat transfer by mixed convection flow of nanofluid in a vertical channel. Malaysian Journal of Fundamental and Applied Sciences 13(3). DOI: https://doi.org/10.11113/mjfas.v16n1.1385.

Rosas, I.Y., Treviño, C. \& Martínez-Suástegui, L. 2017. Experimental study of mixed convection heat transfer in a vertical channel with a one-sided semicylindrical constriction with prescribed heat flux. International Journal of Heat and Fluid Flow 67: 155-167.

Roşca, N.C. \& Pop, I. 2013. Mixed convection stagnation point flow past a vertical flat plate with a second order slip: Heat flux case. International Journal of Heat and Mass Transfer 65: 102-109.

Sajid, M., Pop, I. \& Hayat, T. 2010. Fully developed mixed convection flow of a viscoelastic fluid between permeable parallel vertical plates. Computers \& Mathematics with Applications 59(1): 493-498.
Sharidan, S., Amin, N. \& Pop, I. 2005. G-jitter fully developed combined heat and mass transfer by mixed convection flow in a vertical channel. International Communications in Heat and Mass Transfer 32(5): 657-665.

Sivasamy, A., Selladurai, V. \& Rajesh Kanna, P. 2010. Mixed convection on jet impingement cooling of a constant heat flux horizontal porous layer. International Journal of Thermal Sciences 49(7): 1238-1246.

Wan Nor Zaleha Amin, Ahmad Qushairi Mohammad \& Sharidan Shafie*

Department of Mathematical Sciences

Faculty of Science

Universiti Teknologi Malaysia

81310 UTM Johor Bahru, Johor Malaysia

Muhammad Qasim

COMSATS University Islamabad

Park Road, Tarlai Kalan

455000 Islamabad

Pakistan

*Corresponding author; email: sharidan@utm.my

Received: 27 February 2019

Accepted: 16 January 2020 